\title{
Heated Tobacco Products Create Side-Stream Emissions: Implications for Regulation
}

\author{
Grant O'ConnelI', Peter Wilkinson'1, Kerstin MM Burseg², Stephen J Stotesbury ${ }^{1}$, John D Pritchard ${ }^{1 \star}$ \\ ${ }^{1}$ Imperial Tobacco Ltd, 121 Winterstoke Road, Bristol, BS3 2LL, UK \\ ${ }^{2}$ Reemtsma Cigarettenfabriken GmbH - Imperial Tobacco Group, Albert-Einstein-Ring 7, D-22761, Hamburg, Germany
}

\begin{abstract}
A number of tobacco manufacturers are promoting products where the tobacco is reportedly "heated" rather than burned. It has been claimed that certain heated tobacco products produce only mainstream and no side-stream emissions. In this study we investigated these claims for a commercially available heated tobacco product and, by using a simple experimental design, investigated whether the high temperature heating of the tobacco matrix during product activation and use results in the generation of side-stream emissions. By way of comparison, the Nicorette $®$ inhalator and a leading e-cigarette brand were also investigated. Our findings indicated that a large number of different chemical compounds were released into the airspace around the heated tobacco product when switched on and during consumer use indicating the generation of side-stream emissions. As the public health community has concluded there is no safe level of exposure to tobacco-containing product emissions, this would be of concern and warrants further investigation. Based on our data showing side-stream emissions from the tobacco matrix, the use of heated tobacco products in indoor public places should fall under the same regulations as cigarettes.
\end{abstract}

Keywords: Heated tobacco; Heat-not-burn; E-cigarette; Nicorette; Side-stream emissions; Second-hand smoke; Nicotine; Tobacco

\section{Introduction}

It is well known that when tobacco burns, many thousands of chemicals are released from the tobacco matrix and are inhaled by consumers and bystanders $[1,2]$. It has been stated that the majority of smoking-related diseases are caused not by nicotine but by the generation of harmful or potentially harmful smoke constituents (HPHCs) from the burning of tobacco [3,4]. In response, a number of tobacco manufacturers are promoting products where the tobacco is reportedly "heated" rather than burned in an attempt to reduce HPHC emissions [5-7]. This is not a new concept, as cigarette-based heated tobacco products were first marketed in the USA in the 1980s and proved to be commercially unsuccessful. Heated tobacco products are now being revived and repositioned as an alternative for smokers who may not wish to replace conventional cigarettes with non-tobacco products such as electronic cigarettes (e-cigarettes). While some manufacturers claim heated tobacco products do not produce sidestream emissions, the major component of 'second-hand smoke', this has yet to be independently verified [8-12]. Since the World Health Organisation has stated "there is no safe level of exposure to secondhand tobacco smoke" [13] and the British Medical Association (BMA) has stated that "almost 85 per cent of second-hand smoke is in the form of invisible, odourless gases" [14], claims of an absence of side-stream emissions from heated tobacco products warrants investigation. To that end, we sought to investigate whether or not side-stream emissions were generated by a commercially available heated tobacco product. For comparative purposes, we also investigated the Nicorette inhalator and a leading e-cigarette.

\section{Experimental Section}

The analytical technique Proton Transfer Reaction-Mass Spectrometry (PTR-MS) was used to sample and analyze for any sidestream emissions released to the airspace around an iQOS heated tobacco product with regular Marlboro HeatSticks (manufacturer, Philip Morris International) when activated by the user (but not puffed) and also during product use. Additionally, sampling was conducted for a Nicorette ${ }^{\circledR}$ inhalator (15 mg nicotine replacement aid; manufacturer, McNeil Consumer Healthcare Ltd) and Blu ${ }^{\text {rx }}$ closed system e-cigarette (18 mg nicotine; manufacturer, Fontem Ventures B.V.) All products used in this study were used in accordance with manufacturer's instructions and consumed ad libitum i.e., there was no pre-defined consumption requirement. For each of the different products, a number of replicate puffs were made and representative data from a single puff is shown. In short, the PTR-MS instrument ionizes volatile organic compounds (VOCs) in the gas phase through their reaction with $\mathrm{H}_{3} \mathrm{O}^{+}$ to form protonated VOCs $\left(\mathrm{VOCH}^{+}\right)$which can then be detected by a mass spectrometer [15]. This process can be run on air samples with or without dilution as normal air gases (e.g., $\mathrm{N}_{2}, \mathrm{O}_{2}, \mathrm{CO}_{2}$ ) have a proton affinity less than water and thus are not ionized. Most VOCs have a proton affinity greater than water and therefore are readily ionized and detected [15]. Analyses with PTR-MS can be conducted in realtime and continuously without the need for sample preparation [15]. Airspace analysis was conducted by connecting the PTR-MS inlet to the test chamber and sampling directly. PTR-MS operating conditions were as follows: drift tube voltage, $500 \mathrm{~V}$; drift tube pressure, $2.3 \mathrm{mbar}$; drift tube temperature, $120^{\circ} \mathrm{C}$; drift tube length, $9.3 \mathrm{~cm} ; E / N$ ratio, $130 \mathrm{Td}$ (Townsends; where $E$ is electric field and $N$ is the number density of the gas in the drift tube; $1 \mathrm{Td}=10^{-17} \mathrm{~cm}^{2} \mathrm{~V}$ molecule ${ }^{-1}$ ); inlet temperature, $120^{\circ} \mathrm{C}$. The experimental set-up is outlined in Figure 1.

\section{Results and Discussion}

\section{Qualitative characterization of side-stream emissions}

Following activation of the iQOS heated tobacco product, as per the manufacturer's instructions, a large number of different VOC species across a range of masses were released into the airspace (Figure 2A). This clearly indicates the generation of side-stream emissions when the device is activated but not puffed by the consumer, which

*Corresponding author: John D Pritchard, Imperial Tobacco Ltd, 121 Winterstoke Road, Bristol, BS3 2LL, UK, Tel: 440117-933-7556; E-mail: john.pritchard@uk.imptob.com

Received October 02, 2015; Accepted October 12, 2015; Published October 15 2015

Citation: O'Connell G, Wilkinson P, Burseg KMM, Stotesbury SJ, Pritchard JD (2015) Heated Tobacco Products Create Side-Stream Emissions: Implications for Regulation. J Environ Anal Chem 2: 163. doi:10.4172/2380-2391.1000163

Copyright: (c) 2015 O'Connell G, et al. This is an open-access article distributed under the terms of the Creative Commons Attribution License, which permits unrestricted use, distribution, and reproduction in any medium, provided the original author and source are credited. 


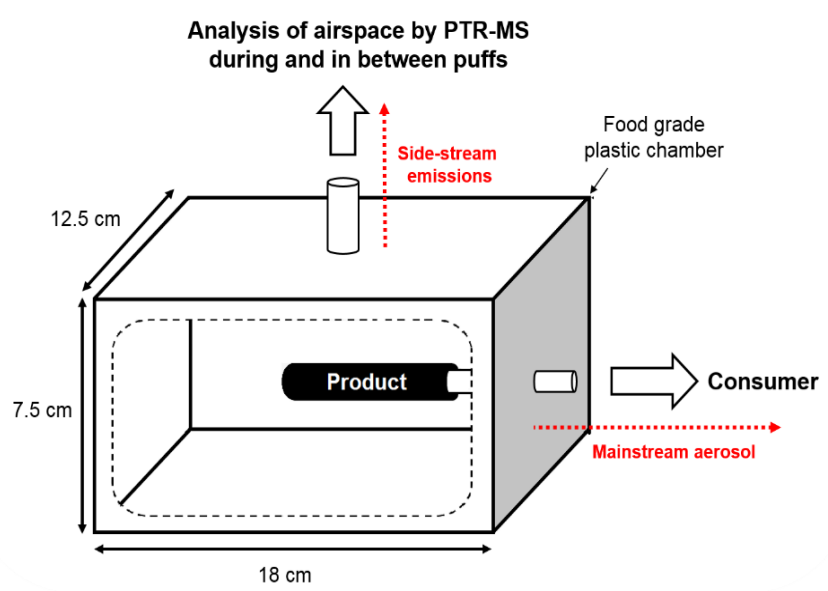

Figure 1: Schematic representation showing experimental set-up and the sidestream emissions capture chamber.

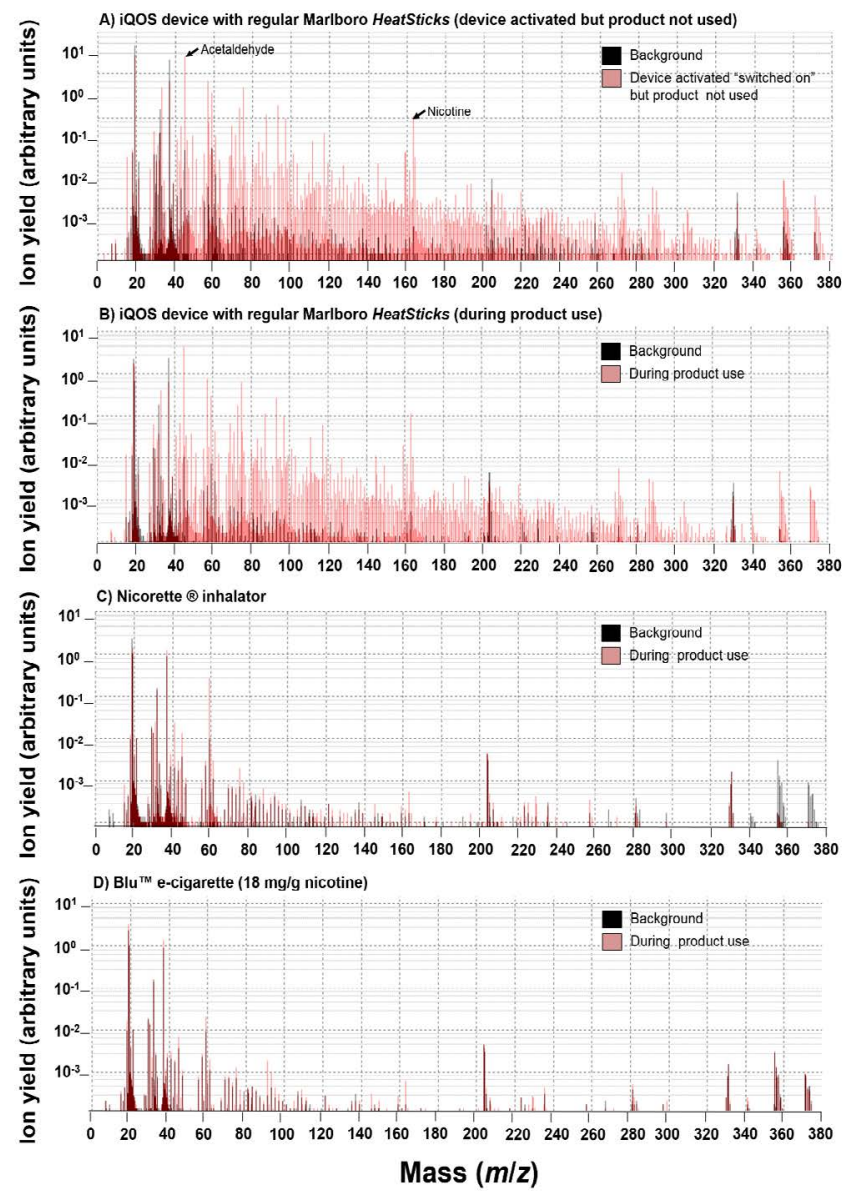

Figure 2: Representative PTR-MS mass spectra of the VOCs released to the airspace for $(\mathbf{A})$ iQOS with regular Marlboro HeatStick when activated "switched on" but product not actively puffed and (B) during consumer use of the iQOS device with regular Marlboro HeatSticks; (C) during consumer use of the Nicorette ${ }^{\circledR}$ inhalator; and (D) during consumer use of the Blu ${ }^{\mathrm{TM}}$ e-cigarette. Specific compound (peaks) at $\mathrm{m} / \mathrm{z} 45$ is protonated acetaldehyde and $m / z 163$ is protonated nicotine and is labelled with arrowheads in (A).

would be released into the ambient air, raising potential concerns for bystanders. Furthermore, during active puffing on the heated tobacco product, side-stream emissions are also released (Figure 2B). These chemicals are being released from the high temperature heating of the tobacco matrix in the HeatSticks. Given the similarities of the Marlboro branded HeatStick used in the iQOS device to a conventional cigarette, the detection of side-stream emissions is perhaps not surprising even though it has been stated that such products produce no side-stream aerosol/smoke [8-12]. Given the findings presented in this pilot study, this requires further investigation.

The PTR-MS mass spectra of the VOCs in the airspace around the Nicorette inhalator (Figure $2 \mathrm{C}$ ) and the e-cigarette (Figure 2D) during product use are virtually indistinguishable. Moreover, the Nicorette ${ }^{\circledR}$ inhalator and the e-cigarette profiles are entirely distinct from that of the heated tobacco product, as may be anticipated given these products do not contain tobacco. The Nicorette ${ }^{\circledR}$ inhalator was selected as an appropriate comparator in this study as the UK Medicines and Healthcare products Regulatory Agency (MHRA) has indicated this should be used as a reference product, if manufacturers intend to license e-cigarettes as medicinal products [16].

\section{Future investigations}

PTR-MS is a one dimensional technique that characterizes VOCs via their mass; to enable identification of the chemicals in the sidestream emissions from the heated tobacco product it is necessary to further calibrate the machine for identification and quantification of compounds of regulatory interest e.g., HPHCs in tobacco products and tobacco smoke as developed by the US Food and Drug Administration (FDA) [17]. We will therefore determine the identities of the many different VOCs released to the airspace, and by extension to the bystander's breathing space, from the heated tobacco product when activated and used by the consumer. Moreover, it is also conceivable that differences in side-stream emissions may be observed under varying user consumption topographies. Further research in these areas will be informative.

\section{Conclusions}

The release of side-stream emissions from heated tobacco products has been observed by PTR-MS using the simple method presented here. These emissions are generated by the high temperature heating of the HeatSticks tobacco matrix inserted within the iQOS device.

The public health community has stated that there is no safe level of exposure to tobacco-containing product emissions $[13,18]$, and so the side-stream constituents including nicotine, released during activation and use of the iQOS heated tobacco product can lead to exposure to bystanders; this would be of concern to public health authorities and warrants further investigation.

It is conceivable that based on these findings and the conclusions of public health community regarding tobacco product emissions, the use of heated tobacco products should be included in smoke-free legislation.

\section{Conflicts of Interest}

The work in this short communication was supported by Imperial Tobacco Group. Imperial Tobacco Group is the parent company of Fontem Ventures B.V. the manufacturer of the e-cigarette used in this study.

\section{References}

1. U.S. Department of Health and Human Services (2014) The health consequences of smoking-50 years of progress: A report of the surgeon general, Atlanta, GA: U.S.

2. U.S. Department of Health and Human Services (2010) How tobacco smoke causes disease: The biology and behavioral basis for smoking-attributable disease: A report of the surgeon general. Atlanta, GA: U.S. 
Citation: O'Connell G, Wilkinson P, Burseg KMM, Stotesbury SJ, Pritchard JD (2015) Heated Tobacco Products Create Side-Stream Emissions: Implications for Regulation. J Environ Anal Chem 2: 163. doi:10.4172/2380-2391.1000163

3. UK National Institute for Health and Care Excellence (2013) Tobacco: Harmreduction approaches to smoking. Public health guidance.

4. http://www.ash.org.uk/files/documents/ASH_715.pdf

5. PMI. Heat-not-burn. Accessed on: 10 August 2015

6. BAT. Tobacco heating products (2015) Accessed on: 10 August 2015

7. JTI. It's time to rethink tobacco (2013) Accessed on: 10 August 2015.

8. Frost-Pineda K, Zedler BK, Liang Q, Roethig HJ (2008) Environmental tobacco smoke (ETS) evaluation of a third-generation electrically heated cigarette smoking system (EHCSS). Regulatory toxicology and pharmacology 52: 118-121.

9. Tricke AR, Schorp MK, Urban HJ, Leyden D, Hagedorn HW, et al. (2009) Comparison of environmental tobacco smoke (ETS) concentrations generated by an electrically heated cigarette smoking system and a conventional cigarette. Inhalation toxicology 21: 62-77.

10. Ginglinger GC, Campelos P, Maeder S, Mitova M, Mottier N, et al. (2015) Indoor air chemistry comparative study between conventional cigarette and heat-not-burn technology. In Global Forum on Nicotine, Warsaw, Poland.

11. Ginglinger GC, Campelos P, Maeder S, Mitova M, Mottier N, et al. (2015) Indoor air chemistry comparative study between conventional cigarette and heat-not-burn technology. In Society of Toxicology Annual Meeting, San Diego, California, USA.
12. Ginglinger GC, Maeder S (2015) Indoor air chemistry (IAC) - comparative study between conventional cigarette and heat-not-burn technology. In Society for Research on Nicotine and Tobacco 21st Annual Meeting, Philadelphia Pennsylvania, USA.

13. WHO (2007) Only $100 \%$ smoke-free environments adequately protect from dangers of second-hand smoke. Accessed on: 10 August 2015.

14. BMA (2002) Towards smoke-free public places. British medical association board of science and education and tobacco control resource centre.

15. Ellis AM, Mayhew CA (2014) Background, in proton transfer reaction mass spectrometry: Principles and applications. John Wiley \& Sons, Inc., Ch Chester, UK.

16. MHRA (2013) Licensing procedure for electronic cigarettes and other nicotine containing products (NCPS) as medicines.

17. FDA (2012) Harmful and potentially harmful constituents in tobacco products and tobacco smoke; established list. Federal register: 20034-20037.

18. U.S. Department of Health and Human Services (2006) The Health Consequences of Involuntary Exposure to Tobacco Smoke: A Report of the Surgeon General. Rockville, MD: U.S. 